\title{
Auditory evoked response correlates of hearing in the parrakeet (Melopsittacus undulatus)
}

\author{
ROBERT J. DOOLING and JAMES K. WALSH \\ St. Louis University, St. Louis, Missouri 63103
}

\begin{abstract}
Computer-averaged auditory evoked brain responses (EBRs) elicited by tones of different frequencies and intensities were recorded from surface electrodes on the skull of unanesthetized parrakeets. The amplitude and latency of all prominent components of the response waveform were measured, and amplitude-intensity and latency-intensity functions were determined using regression lines fitted by the method of least squares. A linear-log relation was apparent between response amplitude and stimulus intensity, and the slope of the amplitude-intensity function varied as a function of the frequency of the stimulating tone. A good correspondence was observed between the species' audibility curve as determined behaviorally and EBR estimates of absolute threshold.
\end{abstract}

There is a considerable amount of electrophysiological data from various levels of the avian auditory system that has been obtained'from both single-unit recordings (Biederman-Thorson, 1970b; Konishi, 1969a, b, 1970; Leppelsack, 1974; Sachs, Young, \& Lewis, 1974; Schwartzkopff, 1968, 1973; Stopp \& Whitfield, 1961) and depth recordings from gross electrodes (Adamo \& King, 1967; Biederman-Thorson, 1970a; Erulkar, 1955; Harman \& Phillips, 1967; Harrison \& Furumoto, 1971; Saunders, Coles, \& Gates, 1973; Saunders, Gates, \& Coles, 1974). Recently, it has been demonstrated that computer-averaged auditory evoked brain responses (EBRs) can be collected from the surface of the avian skull in unanesthetized parrakeets (Dooling, Walsh, \& Tepas, 1975). Recordings from awake birds might show a close correspondence between neural activity and behavior. The wealth of behavioral data on auditory perception in the parrakeet (Dooling, 1973; Dooling \& Saunders, 1975; Saunders \& Dooling, 1974) makes the parrakeet a good candidate for evaluating other nonbehavioral measures of auditory sensitivity.

The EBR has been used as an alternative method for estimating auditory thresholds in both humans and animals which cannot be easily tested behaviorally (Davis, 1968; Davis, Bowers, \& Hirsh, 1968; Davis \& Zerlin, 1966; Henderson, Hamernik, Woodford, Sitler, \& Salvi, 1973; Henderson, Onishi, Eldredge, \& Davis, 1969; Loftus-Hills \& Johnstone,

This paper is based on a PhD thesis presented by Robert Dooling to the Faculty of the Graduate School of Saint Louis University, St. Louis, Missouri, in partial fulfillment of the requirements for the degree of Doctor of Philosophy in Psychology. The authors thank Professor Donald I. Tepas for his helpful criticisms in all phases of this experiment. Requests for reprints should be sent to Robert J. Dooling, Rockefeller University Field Research Center, Tyrrel Road, Millbrook, New York 12545.
1970). The present study was designed to collect EBRs from the skull of unanesthetized parrakeets at a number of frequencies and intensities throughout their range of hearing. These responses are discussed in relation to behavioral studies of parrakeet auditory capability, and a general effort is made to develop a method of EBR audiometry for the parrakeet.

\section{METHOD}

\section{Subjects}

Five commercially available parrakeets (four males and one female), estimated to be about 6 months of age, were used. Each bird was surgically prepared with a monopolar recording electrode assembly (Dooling, Walsh, \& Tepas, 1975). The active, ground, and reference electrodes are shown in Figure 1 in relation to the parrakeet skull and brain. The active electrode was an inverted wire nail (head diam $2 \mathrm{~mm}$ ) cemented to the surface of the skull overlying the neostriatum (Boord, 1969; Karten, 1967, 1968; Schwartzkopff, 1973). The ground and reference electrodes were stainless steel straight pins affixed to the skull just behind the cere.

\section{Testing Environment}

The birds were tested while sitting quietly on a perch in a small wire cage within a sound-deadened chamber. The acoustic details of the sound-deadened chamber, calibration of the sound field, and a full description of the details for testing the birds have appeared elsewhere (Dooling, Walsh, \& Tepas, 1975). The auditory stimuli were tone bursts of 20 -msec duration, having 5 -msec rise and fall times. EBRs were collected to tone bursts at seven frequencies within the parrakeets' range of hearing (Dooling \& Saunders, 1975), and each test frequency was presented at a minimum of eight intensity levels. The test frequencies used were $.5,1.0,2.0,2.8,4.0,5.7$, and $8.0 \mathrm{kHz}$. The actual range of intensities used at each frequency was selected on the basis of pilot experiments to ensure a well-defined response at the lowest intensity tested while attempting to avoid possible saturation effects at the highest intensities used. In practice, intensity was varied in 5-dB steps over at least a $40-\mathrm{dB}$ range. The lowest sound pressure level (SPL) employed was $30 \mathrm{~dB}$ (re $20 \mu \mathrm{N} / \mathrm{m}^{2}$ ) at $2.0 \mathrm{kHz}$, and the highest SPL used was $95 \mathrm{~dB}$ at $8.0 \mathrm{kHz}$. Thus, averaged EBRs were computed at 59 frequencyintensity combinations within the parrakeets' range of hearing. All conditions were administered to each of the five birds. 


\section{SKULL OF PARRAKEET}

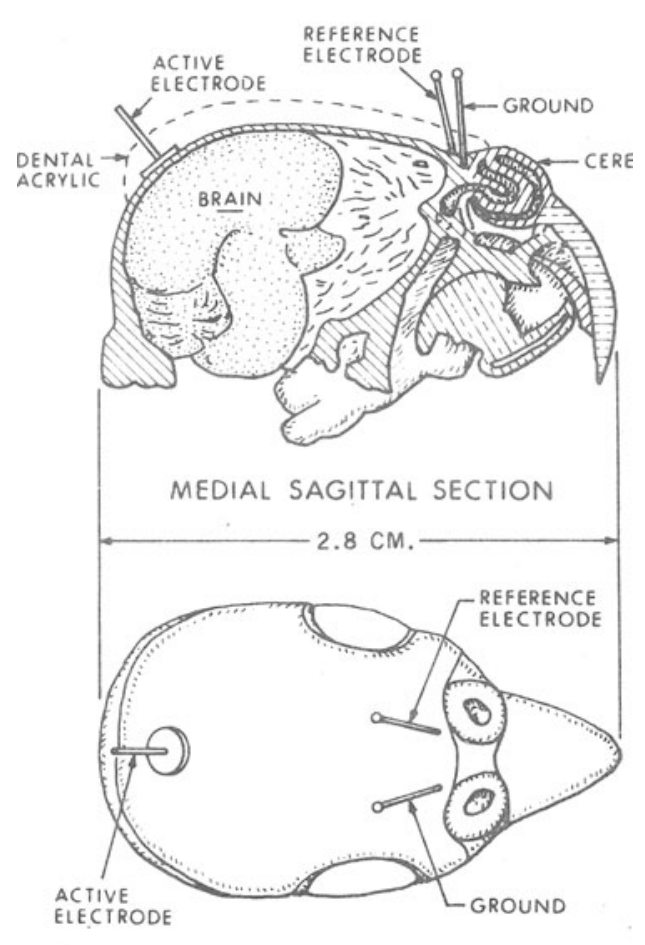

TOP VIEW OF SKULL

Figure 1. Schematic diagram of the parrakeet skull showing the relative positions of the active, ground, and reference electrodes to the parrakeet brain. Porous bone and connective tissue are shown anterior to the brain.

The EEG potentials were amplified by a Grass Model 7 polygraph, using a Model 7P5A wide-band ac preamplifier and were distributed to an AX08 analog input of a Lab-8 computer system (Digital Equipment Corporation). The bandpass of the amplifiers was set to .15 to $500 \mathrm{~Hz}$. A signal-averaging epoch of $200 \mathrm{msec}$ was divided into 200 time points which provided a resolution of $1 \mathrm{point} / \mathrm{msec}$. Averaging was begun $5 \mathrm{msec}$ prior to the onset of the tone burst.

\section{Testing Procedure}

A trial consisted of 250 tone bursts of a particular frequency and intensity presented at the rate of one tone burst every $320 \mathrm{msec}$. At the end of a trial, the stimulus was turned off, the resulting EBR was punched onto paper tape, and the oscillator and attenuators were reset for another trial at a different frequency and intensity. This usually required about 1-2 min. A session, consisting of at least 59 trials, generally required from 5-7 h, and each bird was tested in four such sessions over successive nights. The order of presentation of the 59 frequencyintensity combinations was randomly varied within a daily session, and a different random sequence was used for each session.

After a bird completed four sessions, EBRs were pooled across sessions for each frequency-intensity combination resulting in a single EBR waveform which was the algebraic sum of the EEG responses to 1,000 tone-burst presentations (250 tone bursts for each of four sessions). This procedure for pooling waveforms has been described previously (Tepas, Kress, \& Klingaman, 1975), as has the nomenclature system used for labeling the major features of each EBR waveform (Tepas, 1974).
An example of a pooled waveform labeled according to this nomenclature system is shown in Figure 2 in proper temporal relation to a tone burst. Amplitude Measures a to b, b to c, and $c$ to $d$ were computed from a Teletype printout of each of the pooled waveforms from each bird, as were the latencies to Peaks b, c, and d.

\section{RESULTS}

The EBR waveforms for a single bird (BL) at all frequencies and intensities tested are shown in Figure 3. The major features of these waveforms are similar at all frequencies and intensities. The amplitude of these EBR waveforms as determined from Measure a-b are shown in Figure 4 as a function of SPL at each of the seven frequencies tested. Linear regression lines are fitted to the data points by the method of least squares and the Pearson product moment correlation coefficients, and slopes for each amplitude-intensity function are also shown in Figure 4 . The relation between evoked response amplitude and SPL in decibels can be described by a straight line over the intensity range examined. Similar results were obtained for all five birds across all three amplitude measures. Of the total of 105 correlation coefficients resulting from least-squares fits to the data from individual birds (five birds by seven frequencies by three amplitude measures), 88 of these correlation coefficients were statistically significant, $r(6) \geqslant .707$, $\mathrm{p}<.05$ (McNemar, 1969).

For Amplitude Measure a-b, the mean amplitude for the five birds at each frequency-intensity combination was calculated. These data points are shown in Figure 5 along with correlation coefficients and slopes associated with the least-squares fit at each frequency. The linear-log relation between response amplitude and SPL is quite apparent at all frequencies, with the goodness of fit being evidenced

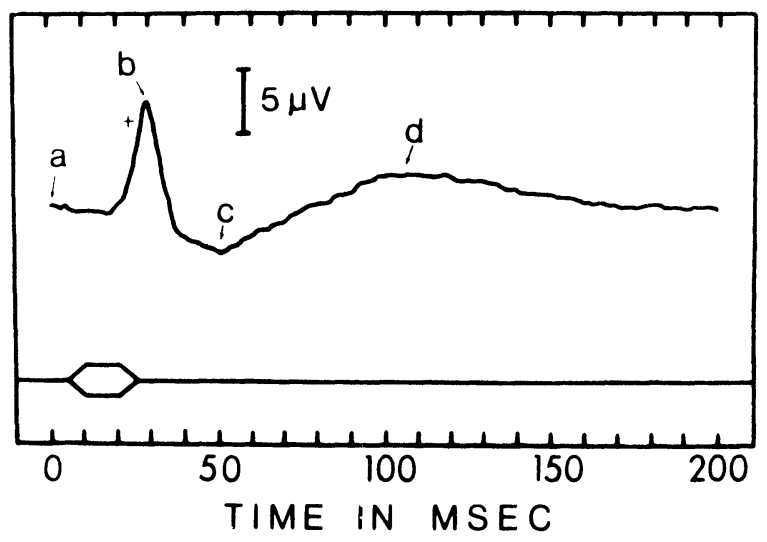

Figure 2. A single EBR waveform obtained by pooling the result of 1,000 stimulus presentations. Deflection labels a, $b$, c, and $d$ are shown along with a polarity designation. Measure b-c might also be labeled $P_{1}-N_{1}$. This waveform is from bird $\mathrm{LB}$ for a 1,000-Hz tone at $80 \mathrm{~dB}$ SPL. 


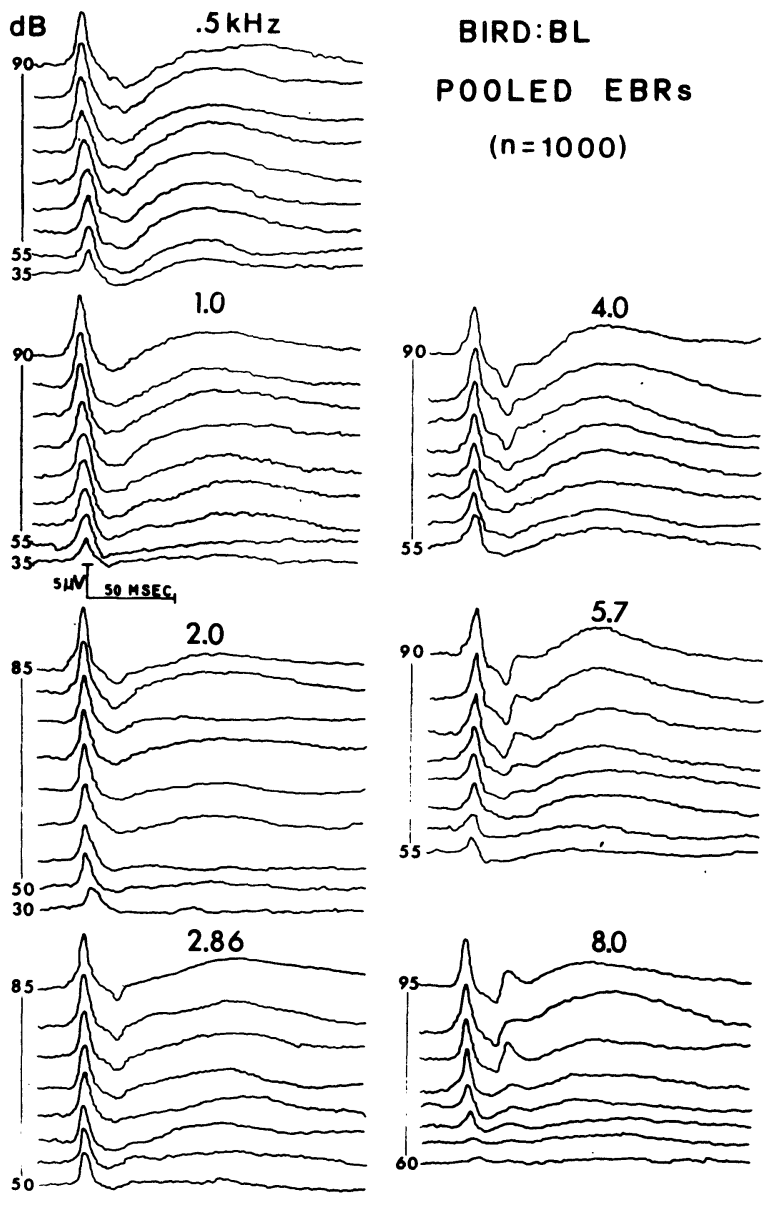

Figure 3. The pooled EBR waveforms $(n=1,000)$ for a single bird (BL) for all frequencies and intensities tested. The calibration markers at $1,000 \mathrm{~Hz}$ refer to all 59 waveforms shown.

by the high correlation coefficients, $r(6) \geqslant .973$, $\mathrm{p}<.001$ (McNemar, 1969). A similar analysis performed on the mean Amplitude Measures b-c and $\mathrm{c}-\mathrm{d}$ to compare relative variability across the three amplitude measures revealed high correlation coefficients for Measure b-c but somewhat lower correlation coefficients for Measure c-d. The mean amplitude-intensity functions calculated for Measure b-c are shown in Figure 6.

While the correlation coefficients associated with regression lines fitted to the mean data points for the waveform Amplitude Measure c-d were lower than those obtained for Measures $a-b$ and $b-c$, the lowest correlation coefficient was nevertheless statistically significant, $\mathrm{r}(6) \geqslant .828, \mathrm{p}<.02$. The amplitude-intensity functions for Measure c-d are not shown but were similar in all major respects to those for Measures $a-b$ and $b$-c. The correlation coefficients for each amplitude measure are shown in Table 1.

The latency to the Waveform Peaks b, c, and d was not as impressively correlated with SPL as was the amplitude of the EBR waveform. The mean latency for the five birds at each frequencyintensity combination was calculated for Peaks b, c, and $\mathrm{d}$ and analyzed in a manner similar to that used for the amplitude data. Regression lines were fitted to the mean data points by the method of least squares and Pearson product moment correlation coefficients were computed for each frequency. In general, higher correlation coefficients were obtained for latency-intensity functions based on Peak b than for Peaks $c$ or $d$. These correlation coefficients are also shown in Table 1 .

The latency to Peak b varied most consistently with the intensity and frequency of the stimulus, and, therefore, these functions were selected for further analysis and are shown in Figure 7 . The data suggest that intensity has less of an effect on the latency of the EBR as frequency is increased. These relations are shown more dramatically in Figure 8 in which latency is plotted as a function of frequency for several iso-SPL curves. Note that at the highest intensity shown, the latency to Peak b varies hardly more than $1 \mathrm{msec}$ over the entire frequency range tested. At lower intensities, the latency to Peak b can be seen to decrease
Figure 4. The EBR waveform amplitudes as computed from Measure a-b for one bird (BL)' at all frequencies and intensities. The least-squares regression fits, correlation coefficients, and slopes are also shown for each amplitude-intensity function. SPL is in decibels re $20 \mu \mathrm{N} / \mathrm{m}^{2}$.

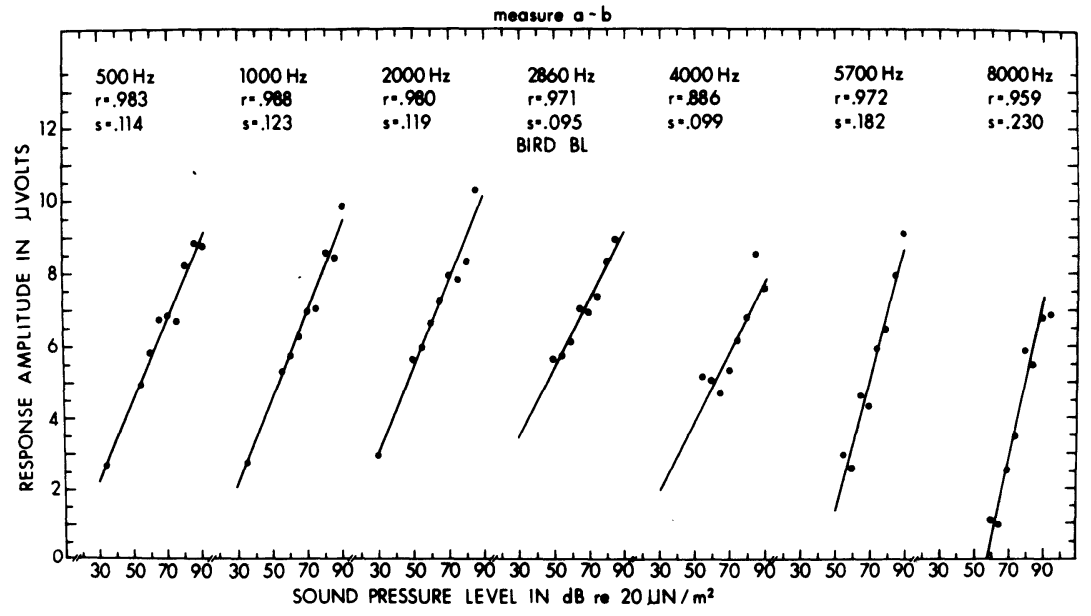


Figure 5. The EBR amplitude-intensity functions based on the mean amplitude for the five birds as computed from Measure a-b. Remaining details are the same as the previous figure.

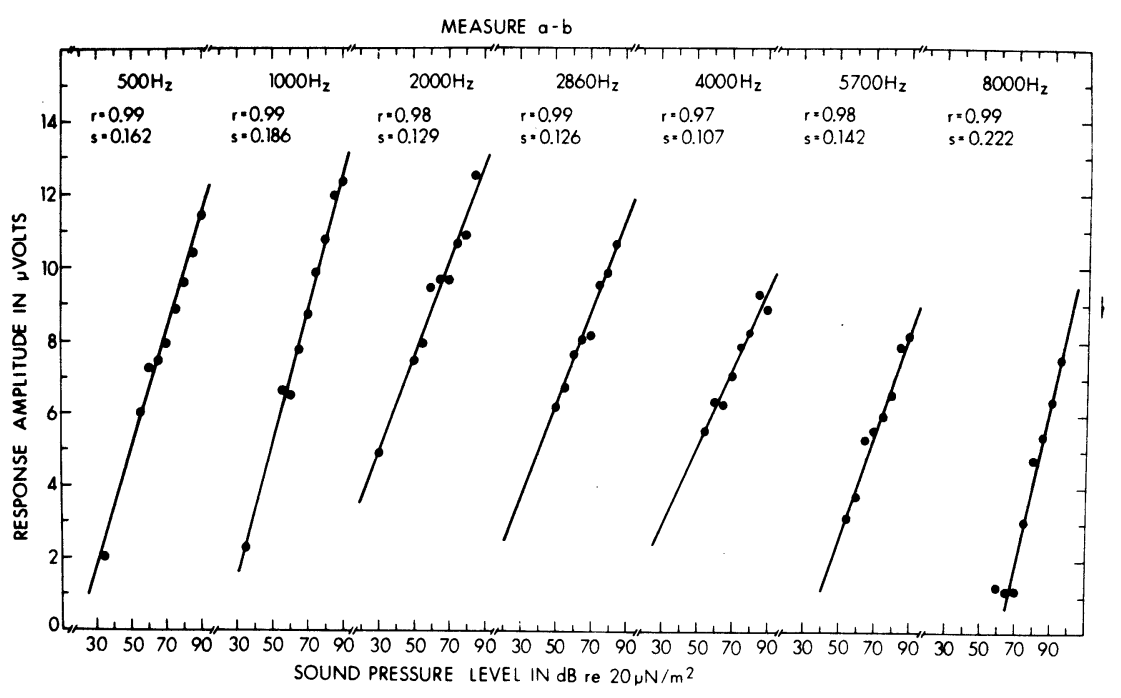

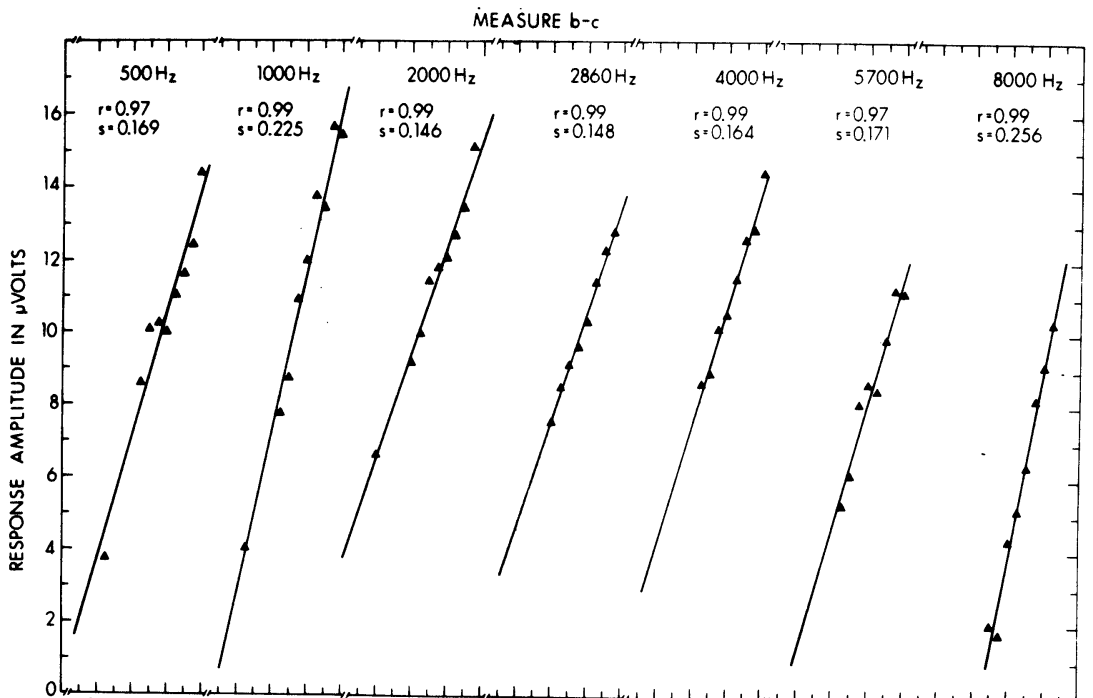

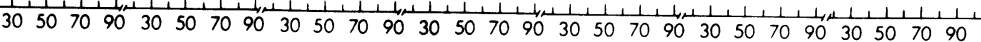
SOUND PRESSURE LEVEL IN $\mathrm{dB}$ re $20 \mu \mathrm{N} / \mathrm{m}^{2}$
Figure 6. The EBR amplitude-intensity functions derived as described in the previous figure from the mean data but for amplitude Measure b-c.
Figure 7. The EBR latency-intensity functions computed from the mean latency to Peak b for the five birds. The least-squares regression fits, correlation coefficients, and slopes for these mean data points are also shown.

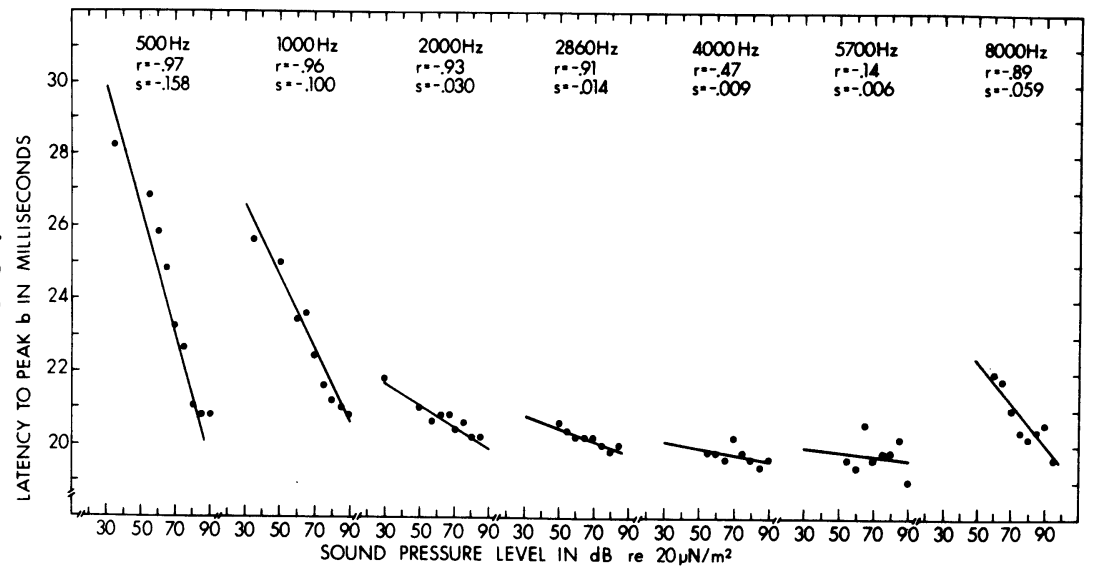


Table 1

Pearson Product Moment Correlation Coefficients for all Amplitude-Intensity and Latency-Intensity Functions Computed from Mean Data

\begin{tabular}{cccccccc}
\hline & \multicolumn{7}{c}{ Frequency in Kilohertz } \\
\cline { 2 - 8 } Measure & .5 & 1.0 & 2.0 & 2.8 & 4.0 & 5.7 & 8.0 \\
\hline \multicolumn{7}{c}{ Amplitude } \\
a-b & .992 & .995 & .984 & .988 & .973 & .984 & .993 \\
b-c & .986 & .987 & .988 & .997 & .990 & .973 & .989 \\
c-d & .895 & .932 & .922 & .828 & .949 & .940 & .992 \\
& \multicolumn{7}{c}{ Latency } \\
b & -.994 & -.969 & -.928 & -.912 & -.466 & -.144 & -.890 \\
c & -.797 & -.322 & -.814 & +.696 & +.519 & +.720 & +.853 \\
d & +.660 & -.341 & -.405 & +.588 & +.382 & +.092 & -.397 \\
\hline
\end{tabular}

Note $-r=.706(p<.05), r=.924(p<.001)$.

more than $5 \mathrm{msec}$ between $500 \mathrm{~Hz}$ and $4.0 \mathrm{kHz}$.

Examination of Table 1 reveals that the latency to Peaks $c$ and $d$ failed to show a consistent relation to either the frequency or intensity of the stimulus. In addition, the variability in the latency to Peaks $c$ and $d$ was greater than for latency to Peak b. Across the 59 frequency-intensity combinations, the mean latency to Peak $\mathrm{C}$ ranged from $38.2 \mathrm{msec}$ to $58.2 \mathrm{msec}$, and the mean latency to Peak d ranged from $90.4 \mathrm{msec}$ to $116.8 \mathrm{msec}$.

The relation between stimulus frequency and intensity and EBR amplitude can also be described using a criterion response method of analysis (Chaffee \& Hampson, 1924; Riggs, Berry, \& Wayner, 1949). For the amplitude-intensity functions shown in Figure 5, the stimulus intensity needed to produce a criterion level of constant response amplitude at each frequency was computed. The isopotential curves shown in Figure 9 were calculated

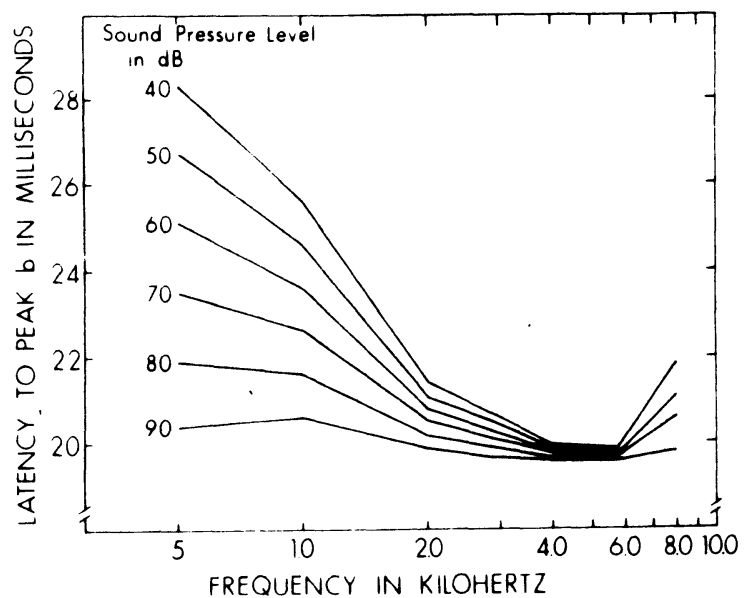

Figure 8. Latency as a function of frequency is shown for several iso-SPL curves. These curves were obtained from the functions presented in the previous figure. The latency to Peak b was computed for a stimulus of the same SPL at each frequency.

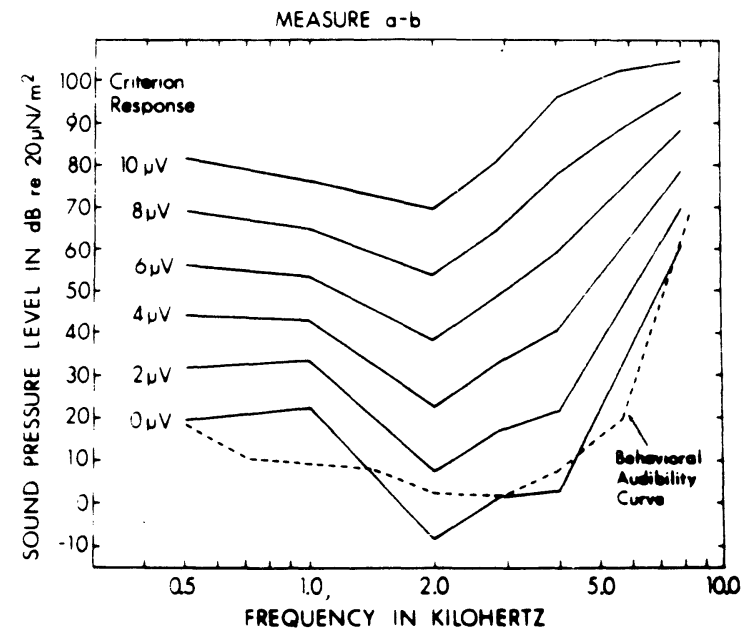

Figure 9. Isopotential curves derived from the mean a-b amplitude data in Figure 5 are shown. The stimulus intensity needed to maintain a constant response amplitude across frequency was computed for six criterion response levels. The dashed line is the behavioral audibility curve replotted from Dooling and Saunders (1975).

in this manner using six different amplitude criteria. The criterion levels chosen are from 0 to $10 \mu \mathrm{V}$, with the $0-\mu \mathrm{V}$ criterion level determined by the linear extrapolation of the regression lines in Figure 5 to the $\mathrm{x}$-intercept. This is not meant to imply, in any way, that the relation between EBR amplitude and SPL is necessarily a linear-log relation at near threshold levels of intensity or that EBR amplitude necessarily falls to zero at the $\mathrm{x}$-intercept. Note that these curves are quite similar in that they all show greatest sensitivity at $2.0 \mathrm{kHz}$ and a rapid decrease in sensitivity above $4.0 \mathrm{kHz}$. Within the range shown, the shape of curves are only slightly affected by the different criterion levels. In fact, the only significant effect of criterion level seems to be at the lower frequencies where $.5 \mathrm{kHz}$ is more sensitive than $1.0 \mathrm{kHz}$ when using the $0-\mu \mathrm{V}$ criterion level, with the reverse being true at higher criterion levels such as $10 \mu \mathrm{V}$.

In a similar fashion, the criterion response method of analysis was applied to the amplitude-intensity functions shown in Figure 6, and the resulting isopotential curves for Measure b-c at seven criterion levels are shown in Figure 10. These curves also show great similarity with the best sensitivity at $2.0 \mathrm{kHz}$ and a high rate of roll-off in sensitivity at the higher frequencies.

The behavioral audibility curve for the parrakeet (Dooling \& Saunders, 1975) is plotted for comparison in Figures 9 and 10. There is a remarkable correspondence between the behavioral audibility curve and all of the criterion response curves computed from both the $a-b$ and $b$-c amplitudeintensity functions. However, the changes in relative sensitivity across frequency as shown by the shape of 


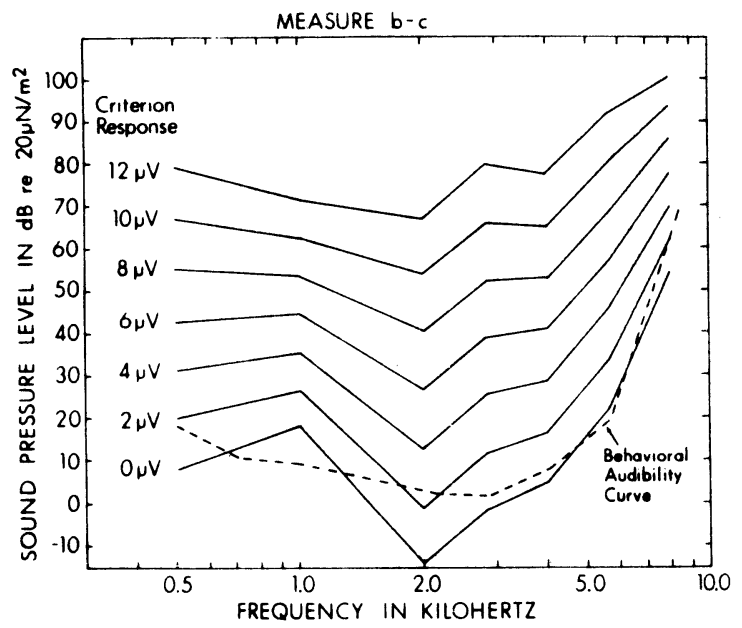

Figure 10. Isopotential curves derived from the functions presented in Figure 6 are shown.

the species' behavioral audibility curve appear to be most closely matched by the intermediate criterion response levels from both the $a-b$ and $b-c$ data. This is due in both cases to the reversal in relative sensitivity across criterion levels at the lower frequencies. Criterion response curves calculated from the c-d amplitude-intensity functions are not shown but, in general, gave considerably poorer fits to the species' audibility curve.

One might expect, intuitively, that the linear extrapolation of the amplitude-intensity functions to the $\mathrm{x}$-intercept at each frequency would serve as a useful EBR definition of absolute auditory sensitivity. Thus, the $0-\mu \mathrm{V}$ criterion response curves shown in Figures 9 and 10 were selected for a more detailed comparison to the behavioral audibility curve. The average difference across frequency between the behavioral audibility curve and the $0-\mu \mathrm{V}$ criterion response curves for Measures $\mathrm{a}-\mathrm{b}$ and $b-c$ is $7.3 \mathrm{~dB}$ and $7.4 \mathrm{~dB}$, respectively. The SPL at each frequency corresponding to these $0-\mu \mathrm{V}$ criterion response curves, the standard errors of estimated intensity from a given response amplitude value, and the deviation from the behavioral threshold at each frequency are listed in Table 2.

Examination of Figures 5 and 6 reveals that the slope of the amplitude-intensity function varies as a function of the stimulus frequency and that, in general, shallower slopes were obtained at those frequencies to which the parrakeet ear is most sensitive while steeper slopes were obtained at frequencies above and below this range. These slopes from amplitude-intensity functions based on all three mean amplitude measures are plotted as a function of frequency in Figure 11. For comparison, the behavioral audibility curve is also shown and should be referred to the right-hand ordinate of Figure 11. These slope values are also listed in Table 3 along with the standard errors of estimated slope at each frequency (McNemar, 1969). As was apparent with the $0-\mu \mathrm{V}$ criterion response curves, the slopes of the regression lines at .5 and $1.0 \mathrm{kHz}$ do not fit the shape of the behavioral audibility curve as well as do the slopes from regression lines from the higher frequencies.

\section{DISCUSSION}

\section{Origin of the Parrakeet EBR}

The origin of the EBRs reported in this study has not been directly or definitively determined. Previous reports based on recordings from gross electrodes at various levels of the avian auditory system suggest that the higher auditory centers in the parrakeet brain may be responsible for the EBRs reported here by virtue of similarities in response latency. These studies report that auditory activity arrives at the caudal surface of the Wulst (Adamo \& King, 1967) with latencies of about $14 \mathrm{msec}$ and at the ovoid nucleus, paleostriatum, and neostriatum (Biederman-Thorson, 1970a; Harman \& Phillips, 1967), with latencies ranging from $10-30 \mathrm{msec}$. These latencies are consistent with the latencies to Peaks b

Table 2

X-Intercept, Standard Errors of Estimated Intensity, and Deviation from Behavioral Threshold at Each Frequency for Measures a-b and b-c

\begin{tabular}{|c|c|c|c|c|c|c|c|}
\hline \multirow[b]{2}{*}{ Statistic* } & \multicolumn{7}{|c|}{ Frequency in Kilohertz } \\
\hline & .5 & 1.0 & 2.0 & 2.8 & 4.0 & 5.7 & 8.0 \\
\hline & & & & $a-b$ & & & \\
\hline $\begin{array}{l}X \text {-intercept } \\
\mathrm{SE}_{\mathbf{x}} \cdot \mathbf{y} \\
\text { Deviation from behavioral threshold }\end{array}$ & $\begin{array}{r}+13.3 \\
2.2 \\
-4.8\end{array}$ & $\begin{array}{r}+21.9 \\
1.7 \\
+13.2\end{array}$ & $\begin{array}{r}-8.9 \\
3.0 \\
-11.7\end{array}$ & $\begin{array}{r}+1.1 \\
1.9 \\
+.9 \\
b-c\end{array}$ & $\begin{array}{r}+2.9 \\
2.9 \\
+3.1\end{array}$ & $\begin{array}{r}+31.9 \\
2.2 \\
+13.4\end{array}$ & $\begin{array}{r}+57.5 \\
1.1 \\
-3.9\end{array}$ \\
\hline $\begin{array}{l}X \text {-intercept } \\
\mathrm{SE}_{\mathbf{x}} \cdot \mathbf{y} \\
\text { Deviation from behavioral threshold }\end{array}$ & $\begin{array}{r}+7.6 \\
4.3 \\
-10.5\end{array}$ & $\begin{array}{r}+18.0 \\
2.7 \\
+9.3\end{array}$ & $\begin{array}{r}-14.7 \\
2.6 \\
-17.5\end{array}$ & $\begin{array}{r}-1.6 \\
.9 \\
-1.8\end{array}$ & $\begin{array}{r}+4.1 \\
1.7 \\
-1.9\end{array}$ & $\begin{array}{r}+22.1 \\
2.9 \\
+3.6\end{array}$ & $\begin{array}{r}+54.4 \\
1.4 \\
-7.0\end{array}$ \\
\hline
\end{tabular}

*All values are in decibels SPL re $20 \mu \mathrm{N} / \mathrm{m}^{2}$. 


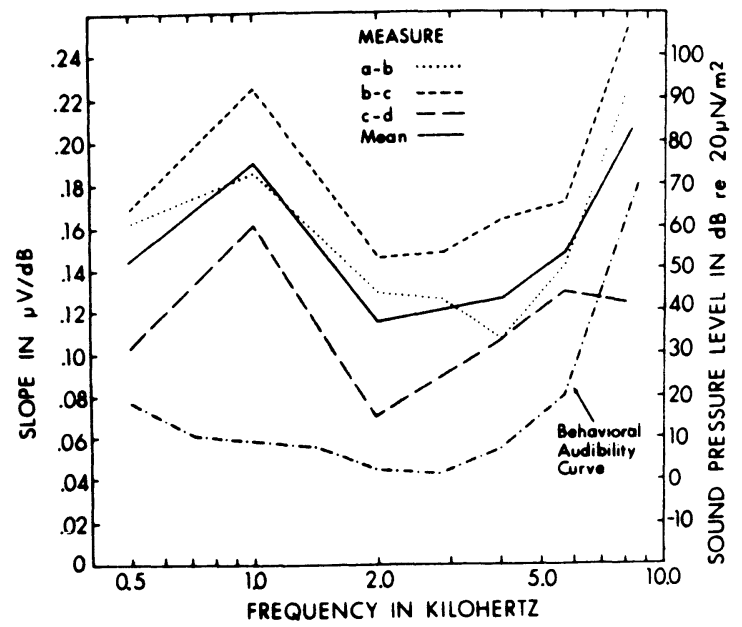

Figure 11. Slopes from amplitude-intensity functions based on mean a-b, b-c, and c-d amplitude measures are shown as a function of frequency. The heavy solid line is the mean slope from the three amplitude measures. The behavioral audibility curve is also shown and should be referred to the right-hand axis.

and $c$ of the parrakeet EBR. However, the possibility cannot definitely be ruled out that the active electrode on the parrakeet skull is picking up activity from some more distant or more peripheral site in the auditory pathway such as the cochlear nucleus.

\section{Latency of the EBR vs. Frequency}

As expected, EBRs to more intense stimuli show slightly shorter latencies, but this effect is only clearly demonstrated for latency to the first Peak $b$. Furthermore, the data also suggest a clear frequency effect on the latency to Peak b. It is tempting to speculate that the increase in latency with decreasing frequency is a reflection of propagation time within the cochlea. At low SPLs, only the apical end of the basilar papilla is effectively stimulated by a $.5-\mathrm{kHz}$ tone. At very high SPLs, on the other hand, a $.5-\mathrm{kHz}$ tone is an effective stimulus for the entire basilar papilla. A similar interpretation can be seen in the results obtained from single-unit recordings in the pigeon auditory nerve (Sachs, Young, \& Lewis, 1974).

An important caveat deserves attention in the interpretation of the parrakeet EBR latency data reported here. The evoked response waveforms were collected and converted to digital values with a resolution of only 1 point $/ \mathrm{msec}$. While at lower frequencies, a 3-5-msec shift in latency was observed over the intensity range examined, the total shift in latency at higher frequencies was usually on the order of $1 \mathrm{msec}$ or less. Thus, while it is reasonable to assume that latency varies less than $1 \mathrm{msec}$ over the intensity range tested at higher frequencies, further assumptions as to the nature of these changes (i.e., slope of the latency-intensity function) should be made with caution.

\section{Power Law vs. Linear-Log Relation}

Whether a power law or a linear-log relation is the best description of EBR amplitude-intensity data has been discussed previously, particularly in regard to the human EBR (Davis, 1974; Davis, Bowers, \& Hirsh, 1968; Keidel \& Spreng, 1965; Rothman, 1970; Tepas, Boxerman, \& Anch, 1972). At best, this issue remains unresolved with the ofteninvoked explanation that the high variability inherent in evoked response research precludes a definitive statement as to which coordinate system gives a better fit. The EBRs reported here are based on a rather large number of EEG samples involving repeated testing of individual animals over a number of days. Furthermore, the intensity range examined was purposely restricted to avoid nonlinearities which might have occurred at very low and very high SPLs. These two strategies undoubtedly forced the attainment of very high positive correlation coefficients between EBR amplitude and SPL. All of the functions presented in this paper were determined using a linear-log coordinate system. It was found, moreover, that a log-log manipulation of the data consistently resulted in lower correlation coefficients between EBR amplitude and SPL. Thus, over the intensity range examined in this experiment, a linearlog relation appears to provide a better overall description of the relation between EBR amplitude and SPL than does a log-log one.

The slope of the amplitude-intensity functions in a linear-log plot was shown to vary as a function of frequency. The fact that the shallowest slopes tended to occur at those frequencies at which the parrakeet ear is most sensitive behaviorally may reflect the fact that the dynamic range of the auditory system is greatest at these same frequencies for the parrakeet. However, the relation between slope and frequency is probably critically dependent on a number of factors including electrode location and

Table 3

Slopes from Amplitude-Intensity Functions Computed from Mean Data

\begin{tabular}{|c|c|c|c|c|c|c|c|}
\hline \multirow[b]{2}{*}{ Statistic } & \multicolumn{7}{|c|}{ Frequency in Kilohertz } \\
\hline & .5 & 1.0 & 2.0 & 2.8 & 4.0 & 5.7 & 8.0 \\
\hline & \multicolumn{7}{|c|}{$a-b$} \\
\hline Slope & .145 & .184 & .128 & .126 & .107 & .142 & .222 \\
\hline \multirow[t]{2}{*}{$S_{\text {slope }}$} & .005 & .006 & .008 & .005 & .006 & .006 & .004 \\
\hline & \multicolumn{7}{|c|}{$b-c$} \\
\hline Slope & .169 & .225 & .146 & .148 & .164 & .171 & .256 \\
\hline \multirow[t]{2}{*}{ SE $E_{\text {slope }}$} & .015 & .013 & .008 & .004 & .009 & .015 & .014 \\
\hline & \multicolumn{7}{|c|}{$c-d$} \\
\hline Slope & .103 & .161 & .071 & .089 & .106 & .129 & .124 \\
\hline SE slope & .018 & .022 & .011 & .024 & .013 & .018 & .006 \\
\hline
\end{tabular}

Note-All values are in microvolts per decibel. 
number of EEG samples averaged. No attempt was made in the present study to assess the influence of these factors, and it may be that the poor correlation between slope and frequency observed at the lower frequencies is due to one or more of these factors.

\section{EBRs and Behavioral Sensitivity}

The $x$-intercept extrapolations of the EBR amplitude-intensity functions were shown to exhibit a close relation to the parrakeets' absolute threshold as determined behaviorally. Measures $a-b$ and $b-c$ gave closer fits in this regard than did Measure c-d. While the notion of estimating absolute sensitivity from extrapolation to $0-\mu \mathrm{V}$ response amplitude is not new, the procedure as employed in the present experiment may have advantages over more commonly used methods of estimating threshold from EBRs.

The use of the visual detection level of threshold estimation often requires a decision by two or three judges as to whether or not an evoked response has occurred. Likewise, the arbitrary nature of choosing, beforehand, a fixed criterion level (i.e., a two-to-one signal-to-noise ratio) has an inherent disadvantage in that the threshold is predetermined by the criterion level selected. The present method allows one to examine the effect of any number of response criterion levels on relative frequency sensitivity. In addition, the utilization of a Teletype printout of the decimal values of the EBR waveform as a source for data values minimizes the problem of loss of measurement precision at low levels of response.

Finally, since EBRs from the parrakeet have been shown to have a good correspondence to the parrakeet's auditory capability, and since the birds in this experiment were unanesthetized, these same procedures should be useful in examining the relation between neural activity and the perception of more biologically significant sounds such as the species' vocalizations.

\section{REFERENCES}

Adamo, N. J., \& King, R. L. Evoked responses in the chicken telencephalon to auditory, visual and tactile stimulation. Experimental Neurology, 1967, 17, 498-504.

Biederman-Thorson, M. Auditory evoked responses in the cerebrum (Field $\mathrm{L}$ ) and the ovoid nucleus of the ring dove. Brain Research, 1970, 24, 235-245. (a)

Biederman-Thorson, M. Auditory responses of units in the ovoid nucleus and cerebrum (Field L) of the ring dove. Brain Research, 1970, 24, 247-256. (b)

BoorD, R. L. Anatomy of the avian auditory system. Annals of the New York Academy of Sciences, 1969, 68, 186-198.

Chaffee, E. L., \& Hampson, A. Effects of varying the wavelength of the stimulating light upon the electrical response of the retina. Journal of the Optical Society of America, 1924, 9, 1-25.
DAvis, H. Averaged evoked response EEG audiometry in North America. Acta Oto-Laryngologica, 1968, 65, 79-85.

DAvis, H. Sedation of young children for electric response audiometry (ERA). A udiology, 1973, 12, 55-57.

DAvIs, H. Relations of peripheral action potentials and cortical evoked potentials to the magnitude of sensation. In H. R. Rasokowitz, B. Scharf, \& J. C. Stevens (Eds.), Sensation and measurement: Papers in honor of S. S. Stevens. Boston: Reidel, 1974. Pp. 37-47.

Davis, H., Bowers, C., \& Hirsh, S. K. Relations of the human vertex potential to acoustic input: Loudness and masking. Journal of the Acoustical Society of America, 1968, 43, 431-438.

DAvis, H., \& ZerLin, S. Acoustic relations of the human vertex potential. Journal of the Acoustical Society of America, 1966, 39, 109-116.

Dooling, R. J. Behavioral audiometry with the parakeet (Melopsittacus undulatus). Journal of the Acoustical Society of America, 1973, 53, 1757-1758.

Dooling, R. J., \& S Aunders, J. C. Hearing in the parakeet (Melopsittarus undulatus); Absolute thresholds, critical ratios, frequency difference limens, and vocalizations. Journal of Comparative and Physiological Psychology, $1975,88,1-20$.

Dooling, R. J., Walsh, J. K., \& Tepas, D. I. Auditory evoked brain responses from the parakeet: Intensity functions. Physiological Psychology, 1975, 3, 307-311.

ERULKAR, S. K. Tactile and auditory areas in the brain of the pigeon. Journal of Comparative Neurology, 1955, 103, 421-457.

Harman, A. L., \& Phillips, R. E. Responses in the avian midbrain, thalamus, and forebrain evoked by click stimuli. Experimental Neurology, 1967, 18, 276-286.

Harrison, J. B., \& Furumoto, L. Pigeon audiograms: Comparison of evoked potential and behavioral thresholds in individual birds. Journal of Auditory Research, 1971, $11,33-42$.

Henderson, D., Hamernik, R. P., Woodford, C., Sitler, R. W., \& SALvi, R. The evoked response audibility curve of the chinchilla. Journal of the Acoustical Society of America, 1973, 54, 1099-1101.

Henderson, D., Onishi, S., Eldoredge, D. H., \& Davis, H. A comparison of chinchilla evoked response and behavioral thresholds. Perception \& Psychophysics, 1969, 5, 41-45.

KARTEN, H. J. The organization of the ascending auditory pathway in the pigeon (Columba livia). I. Diencephalic projections of the inferior colliculus (nucleus mesencephalic lateralis pars dorsalis). Brain Research, 1967, 6, 409-427.

KARTEN, H. J. The ascending auditory pathway in the pigeon (Columba livia). II. Telencephalic projections of the nuclei ovoidalis thalami. Brain Research, 1968, 11, 134-153.

Keidel, W. D., \& SpReng, M. Neurophysiological evidence for the Stevens power function in man. Journal of the Acoustical Society of America, 1965, 38, 191-195.

Konishi, M. Hearing, single-unit analysis, and vocalizations in songbirds. Science, 1969, 166, 1178-1181. (a)

Konishi, M. Time revolution by single auditory neurones in birds. Nature, 1969, 222, 566-567. (b)

KonISHI, M. Comparative neurophysiological studies of hearing and vocalizations in songbirds. Zeitschrift für vergleichende Physiologie, 1970, 66, 257-272.

LeppelsacK, H. J. Funktionelle Eigenschaften der Hoerbahn im Feld L des Neostriatum caudale des Staren (Sturnus vulgaris L., Aves). (Functional properties of the acoustic pathway in the Field $\mathrm{L}$ of the neostriatum caudale of the starling (Sturnus vulgaris $\mathrm{L}$. Aves). Journal of Comparative Physiology, 1974, 88, 271-320.

Loftus-Hills, J. J., \& Johnstone, B. M. Auditory function. communication and the brain evoked response in anuran amphibians. Journal of the Acoustical Society of America, 1970, 47, 1131-1138.

McNemar, Q. Psychological statistics. New York: Wiley, 1969.

Riggs, L. A., BerRY, R. N., \& WAYNer, M. A. A comparison of electrical and psychophysical determinations of the 
spectral sensitivity of the human eye. Journal of the Optical Society of America, 1949, 39, 427-436.

Rothman. H. H. Effects of high frequencies and intersubject variability of the auditory-evoked cortical response. Journal of the Acoustical Society of America, 1970, 47, 569-573.

SAChs. M. B., Young, E. D., \& Lewis, R. H. Discharge patterns of single fibers in the pigeon auditory nerve. Brain Research, 1974, 70, 431-447.

Saunders, J. C., Coles, R. B., \& Gates, G. R. The development of auditory evoked responses in the cochlear nuclei of the chick. Brain Research, 1973, 63, 59-74.

Saunders, J. C., Gates, G. R., \& Coles, R. B. Brainstem evoked responses as an index of hearing thresholds in oneday-old chicks and ducklings. Journal of Comparative and Physiological Psychology, 1974, 86, 426-431.

Saunders, J. C.. \& Dooling, R. J. Noise-induced threshold shift in the parakeet (Melopsittacus undulatus). Proceedings of the National Academy of Sciences, 1974, 71, 1962-1965.

SchwartzkopfF, J. Structure and function of the ear and of the auditory brain areas in birds. In A. V. S. DeReuck \& Julie Knight (Eds.), Hearing mechanisms in vertebrates. Boston: Little, Brown, 1968. Pp. 41-63.
Schwartzkopff, J. Mechanoreception. In D. S. Farmer, J. R. King. \& K. C. Parkes (Eds.), Avian biology III. New York: Academic Press, 1973. Pp. 417-477.

Stopp, P. E., \& Whitfield, I. C. Unit responses from brainstem nuclei in the pigeon. Journal of Physiology (London), 1961, 158, 165-177.

Tepas, D. I. Computer analysis of the electroencephalogram: Evoking. promoting and provoking. Behavior Research Methods \& Instrumentation, 1974, 6, 95-110.

Tepas, D. I., Boxerman, L. A., \& Anch, A. M. Auditory evoked brain responses: Intensity functions from bipolar human scalp recordings. Perception \& Psychophysics, 1972. 11. $217-221$.

Tepas, D. I.. Kress, G., \& Klingaman, R. L. APE: Average potential evaluation software for the Lab-8 system. Behavior Research Methods \& Instrumentation, 1975, 7, 120-124.

(Received for publication November 8. 1975; revision accepted March 2, 1976.) 